\title{
Synthesis and techno-economic assessment of microbial-based processes for terpenes production
}

\author{
Wenzhao Wu and Christos T. Maravelias* (1)
}

\begin{abstract}
Background: Recent advances in metabolic engineering enable the production of chemicals from sugars through microbial bio-conversion. Terpenes have attracted substantial attention due to their relatively high prices and wide applications in different industries. To this end, we synthesize and assess processes for microbial production of terpenes.
\end{abstract}

Results: To explain a counterintuitive experimental phenomenon where terpenes such as limonene (normal boiling point $176^{\circ} \mathrm{C}$ ) are often found to be $100 \%$ present in the vapor phase after bio-conversion (operating at only $\sim 30^{\circ} \mathrm{C}$ ), we first analyze the vapor-liquid equilibrium for systems containing terpenes. Then, we propose alternative production configurations, which are further studied, using limonene as an example, in several case studies. Next, we perform economic assessment of the alternative processes and identify the major cost components. Finally, we extend the assessment to account for different process parameters, terpene products, ways to address terpene toxicity (microbial engineering vs. solvent use), and cellulosic biomass as a feedstock. We identify the key cost drivers to be (1) feed glucose concentration (wt\%), (2) product yield (\% of maximum theoretical yield) and (3) VVM (Volume of air per Volume of broth liquid per Minute, i.e., aeration rate in $\mathrm{min}^{-1}$ ). The production of limonene, based on current experimental data, is found to be economically infeasible (production cost $\sim 465 \$ / \mathrm{kg}$ vs. market selling price $\sim 7 \$ / \mathrm{kg}$ ), but higher glucose concentration and yield can lower the cost. Among 12 terpenes studied, limonene appears to be the most reasonable short-term target because of its large market size ( 160 million \$/year in the US) and the relatively easier to achieve break-even yield ( 30\%, assuming a $14 \mathrm{wt} \%$ feed glucose concentration and $0.1 \mathrm{~min}^{-1} \mathrm{VVM}$ ).

Conclusions: The methods proposed in this work are applicable to a range of terpenes as well as other extracellular insoluble chemicals with density lower than that of water, such as fatty acids. The results provide guidance for future research in metabolic engineering toward terpenes production in terms of setting targets for key design parameters.

Keywords: Isoprenoid, Terpenoid, Limonene, Process systems engineering, Process simulation, Microbial production, Vapor liquid equilibrium, Biphasic fermentation, Fatty acids

\footnotetext{
*Correspondence: maravelias@wisc.edu

Dept. of Chemical and Biological Engineering and DOE Great Lakes

Bioenergy Research Center, University of Wisconsin-Madison, 1415

Engineering Drive, Madison, WI 53706, USA
} 


\section{Background}

Recent advances in metabolic engineering enable the use of microbes such as E. coli and S. cerevisiae for the production of chemicals [1-12]. Compared to traditional fossil fuel-based processes, bio-processes can be advantageous for their mild production conditions and good selectivity toward a specific product [13]. Also, the chemicals can be produced directly using microbes instead of being converted via multiple conversion steps (some of which can have low yield and high cost) from fossil fuel feedstocks.

Terpenes (also known as isoprenoids or terpenoids) are a class of organic compounds biosynthetically derived from isoprene $\left(\mathrm{C}_{5} \mathrm{H}_{8}: \mathrm{CH}_{2}=\mathrm{C}\left(\mathrm{CH}_{3}\right)-\mathrm{CH}=\mathrm{CH}_{2}\right)$ and can be classified into groups according to the number of carbons they contain: hemiterpene $\left(C_{5}\right.$, i.e., isoprene), monoterpenes $\left(C_{10}\right.$; major interest of many studies), sesquiterpenes $\left(C_{15}\right)$, diterpenes $\left(C_{20}\right)$, triterpenes $\left(C_{30}\right)$, etc. [14-17]. Terpenes have been attracting substantial attention due to their relatively high prices and wide applications in chemical, food, cosmetics, pharmaceutical, fragrance, flavor and biotechnology industries [14, 1823]. Some terpenes, such as limonene and linalool, are also potential drop-in biofuels and platform chemicals to produce other value-added products [24-26].

The microbial conversion of terpenes from sugar via microbes has been reviewed extensively [14, 27-36]. Terpenes can be produced mainly via the mevalonate pathway, or 1-deoxy-D-xylulose-5-phosphate (DXP) pathway. Most terpenes are produced extracellularly, and they are insoluble and lighter (in terms of density) than water, thus forming a top oil phase in the liquid fermentation broth.
Note that we do not consider the special case where terpenes fail to form a separate phase from water due to the presence of surface active impurities in the broth. Recent studies indicate that the fermenter can be tuned to favor globule coalescence and thus the formation of a separate phase [37-39]. Also, microbial production of terpenes has demonstrated high selectivity toward a specific product [40]. Although intracellular components (such as amino acids and nucleoids) will be released after cell death, compounds that are insoluble and lighter than water (as the terpene product is), mainly lipids, are actually bound to the cell membrane debris and settle to the bottom, and are thus naturally separated from the product (on the top). Therefore, downstream separation cost tends to be relatively low. In addition, several terpenes (such as limonene and pinene) were estimated to have the potential to reach a promising profit margin in a recent study that identifies economically promising biobased chemicals [41].

The major properties as well as the market price and volume data for selected terpenes are presented in Table 1. It can be seen that limonene has a relatively large market size and price. Limonene is commonly used as a flavor, insecticide, solvent (employed in adhesives, stain removers and household cleaners), etc. [40]. Most limonene currently on the market is D-limonene (mainly technical grade, with $95 \mathrm{wt} \%$ purity), obtained as a byproduct of citric fruit juice production through citrus peel cold-press followed by centrifugation or by steam distillation followed by condensation [24, 40, 42-47]. However, limonene availability, quality and price (3-11 \$/ $\mathrm{kg}$ [24], with an average of $7 \$ / \mathrm{kg}$ ) fluctuate substantially

Table 1 US market data and properties of selected terpenes

\begin{tabular}{|c|c|c|c|c|c|c|c|c|}
\hline Terpene & Formula & $\begin{array}{l}\text { Market } \\
\text { price (\$/ } \\
\text { kg) }\end{array}$ & $\begin{array}{l}\text { Market volume } \\
\left(10^{6} \mathrm{~kg} / \text { year }\right)\end{array}$ & $\begin{array}{l}\text { Market size } \\
\left(10^{6} \$ / \text { year }\right)\end{array}$ & $\begin{array}{l}\text { Max. yield } \\
\text { (g product/g } \\
\text { glucose) }\end{array}$ & Density (g/L) & $\begin{array}{l}\text { Solubility } \\
\left(\mathrm{g} / \mathrm{L}, 25^{\circ} \mathrm{C}\right)\end{array}$ & $\begin{array}{l}\text { Boiling point } \\
\left({ }^{\circ} \mathrm{C}, 1 \text { atm }\right)\end{array}$ \\
\hline Isoprene & $\mathrm{C}_{5} \mathrm{H}_{8}$ & 1.2 & 173 & 208 & 0.32 & 681 & 0.3 & 34 \\
\hline D-Limonene & $\mathrm{C}_{10} \mathrm{H}_{16}$ & 7 & 23 & 160 & 0.32 & 842 & Insoluble & 176 \\
\hline$\beta$-Pinene & $\mathrm{C}_{10} \mathrm{H}_{16}$ & 5 & 20 & 102 & 0.32 & 868 & Insoluble & 167 \\
\hline a-Pinene & $\mathrm{C}_{10} \mathrm{H}_{16}$ & 2.5 & 22 & 56 & 0.32 & 860 & Insoluble & 155 \\
\hline Linalool & $\mathrm{C}_{10} \mathrm{H}_{18} \mathrm{O}$ & 4.5 & 8.6 & 39 & 0.37 & 863 & 0.7 & 198 \\
\hline Squalene & $\mathrm{C}_{30} \mathrm{H}_{50}$ & 34 & 0.5 & 17 & 0.32 & 858 & Insoluble & 429 \\
\hline ү-Bisabolene & $\mathrm{C}_{15} \mathrm{H}_{24}$ & 160 & $<0.5$ & $<73$ & 0.32 & 890 & Insoluble & 261 \\
\hline Lycopene & $\mathrm{C}_{40} \mathrm{H}_{56}$ & 100 & $<0.5$ & $<50$ & 0.33 & 889 & Insoluble & 661 \\
\hline a-Humulene & $\mathrm{C}_{15} \mathrm{H}_{24}$ & 50 & $<0.5$ & $<23$ & 0.32 & 889 & Insoluble & 276 \\
\hline Valencene & $\mathrm{C}_{15} \mathrm{H}_{24}$ & 50 & $<0.5$ & $<23$ & 0.32 & 916 & Insoluble & 271 \\
\hline 3-Carene & $\mathrm{C}_{10} \mathrm{H}_{16}$ & 45 & $<0.5$ & $<23$ & 0.32 & 867 & Insoluble & 169 \\
\hline Y-Terpinene & $\mathrm{C}_{10} \mathrm{H}_{16}$ & 35 & $<0.5$ & $<16$ & 0.32 & 849 & Insoluble & 182 \\
\hline
\end{tabular}

The market price and volume estimates are based on the ICIS [49], CDAT [50], Alibaba.com, and IUR [51] databases. Limited volume data are available for low-volume chemicals, so only an upper bound is presented. The market size is the price multiplied by the market volume 
due to fruit bacterial disease infections and pesticides pollution [48].

Microbial production of limonene poses great potential in addressing such issues and thus has been the focus of many studies [16, 48, 52-61]. Several downstream separation methods have also been reported on laboratory scale, including culture extraction, solvent overlay, solid-phase micro-extraction, adsorbent polydimethylsiloxane bar, and continuous headspace removal using a cold trap [43, 60, 62-65]. However, studies on large-scale separation process synthesis and assessment of the entire production process have been limited [37]. In addition, a systematic analysis on a counterintuitive experimental phenomenon is still lacking: terpenes such as limonene are often found to be $100 \%$ present in the vapor phase after bio-conversion, despite limonene's normal boiling point being $176{ }^{\circ} \mathrm{C}$ and the reactor operating temperature being only $\sim 30{ }^{\circ} \mathrm{C}$. Therefore, in this work, we analyze the vaporliquid equilibrium for systems containing terpenes, synthesize alternative processes for microbial terpenes production, and perform techno-economic assessment, thereby identifying major cost drivers and key insights for all alternative process configurations.

The outline of this paper is as follows. In the "Methods" section, we discuss the bio-conversion process and analyze the vapor-liquid equilibrium and its implications on downstream separations. In the "Results and discussion" section, we present three process configurations, which are demonstrated using limonene and perform economic assessment. This is followed by an expanded study, where the costs and the corresponding process configurations in the entire feasible space, defined in terms of three key process parameters, are analyzed. Finally, we generalize our discussion to account for other terpenes, microbes, bio-conversion systems, ways to address terpene toxicity on microbes, and cellulosic biomass as a feedstock.

\section{Methods}

The entire microbial terpene production process consists of upstream bio-conversion and downstream separations. We assume $40 \mathrm{~T} / \mathrm{h}$ ("T"=metric ton) glucose supplied to the bio-conversion system (which can involve multiple fermenters in parallel), where a terpene product is produced by a microbe such as E. coli or S. cerevisiae. We choose a rate of $40 \mathrm{~T} / \mathrm{h}$ because this is the amount of sugar produced by hydrolyzing $2000 \mathrm{~T} /$ day biomass in the NREL study [66], which we use as the basis of our bio-refinery capacity. Our goal is to obtain a technical grade terpene product (e.g., $\geq 95 \mathrm{wt} \%$ for limonene) after downstream separations.

\section{Bio-conversion process}

Glucose, water, and air are fed into the fermenter, assumed to be operated at $30{ }^{\circ} \mathrm{C}$ and $1 \mathrm{~atm}$, as shown in Fig. 1 . We assume three major reactions [61, 66-68]: cell growth (Eq. 1), terpenes production (Eq. 2, with limonene as an example), and microbial respiration (Eq. 3).

As a case study, we consider limonene $\left(\mathrm{C}_{10} \mathrm{H}_{16}\right)$ production using E. coli $\left(\mathrm{CH}_{1.77} \mathrm{O}_{0.49}\right)$ [61].

$$
\begin{gathered}
\mathrm{C}_{6} \mathrm{H}_{12} \mathrm{O}_{6} \rightarrow 6 \mathrm{CH}_{1.77} \mathrm{O}_{0.49} \\
+0.69 \mathrm{H}_{2} \mathrm{O}+1.19 \mathrm{O}_{2} \quad(x \% \text { extent }) \\
7 \mathrm{C}_{6} \mathrm{H}_{12} \mathrm{O}_{6} \rightarrow 3 \mathrm{C}_{10} \mathrm{H}_{16}+12 \mathrm{CO}_{2}+18 \mathrm{H}_{2} \mathrm{O} \\
\\
\mathrm{C}_{6} \mathrm{H}_{12} \mathrm{O}_{6}+6 \mathrm{O}_{2} \rightarrow 6 \mathrm{H}_{2} \mathrm{O}+6 \mathrm{CO}_{2} \quad(z \% \text { extent }) \\
\end{gathered}
$$

where Eq. 1 is adopted from the NREL study for Z. mobilis [66] and modified for E. coli, and the reaction extents are with respect to glucose consumptions. In Willrodt et al. [61], after $45 \mathrm{~h}$ of aerated fermentation with $14 \mathrm{wt} \%$ glucose concentration in the feed, glucose is depleted, while the concentrations of $E$. coli cells and limonene (extracellular) reach their maximum, and no co-products are found. The cell growth extent is $\sim 46.8 \%$ (i.e., $x=46.8$ ). The glucose-to-limonene yield is $\sim 0.45 \%$ of the theoretical stoichiometric maximum yield of $0.32 \mathrm{~g}$ limonene/g glucose (i.e., limonene production extent is $0.45 \% ; y=0.45$ ). The respiration extent is $\sim 52.75 \%$ (i.e., $z=52.75)$.

For the discussions hereafter, we assume that glucose is always depleted after fermentation, i.e., $x+y+z=100$. Microbial respiration (Eq. 3) is the major energy source for cell growth (Eq. 1) [67, 68]. In Willrodt et al. [61], $x: z=1: 1.13$, which is assumed to be a fixed ratio in our current work, and thus the yield $(y \%)$ uniquely determines the other reaction extents as shown in Eq. 4. The ratio can be readily adjusted to account for different microbes, products, etc.

$$
x=\frac{100-y}{2.13}, \quad z=\frac{100-y}{1.88}
$$

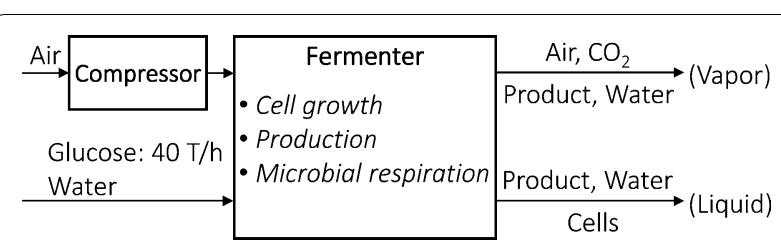

Fig. 1 Bio-conversion process of terpene production, with 40 T/h glucose supply 
Also note that enough air has to be supplied to meet the oxygen requirement of Eq. 3. The minimum amount of air required ( $q_{\mathrm{air}}^{\mathrm{MIN}}, \mathrm{L}$ air/g glucose) is given in Eq. 5. A common parameter describing air supply is aeration rate VVM $\left(\min ^{-1}\right)$-volume of air per volume of liquid per minute, which thus has a lower bound (VVM $\left.{ }^{\mathrm{MIN}}\right)$ to satisfy the air requirement. See the deduction and expressions of $q_{\text {air }}^{\mathrm{MIN}}$ and $\mathrm{VVM}^{\mathrm{MIN}}$ in "Background" section of Additional file 1 .

$$
q_{\mathrm{air}}^{\mathrm{MIN}}=0.0167 \times(100-y)
$$

The supply of nitrogen and phosphorus nutrients (e.g., using diammonium phosphate) for cell growth is neglected here because the cost is negligible (less than $1 \%$ of the total operating cost in the NREL study). Also, we assume continuous operation of the fermenter (i.e., chemostat). Experimental data obtained based on batch or fed-batch reactors (e.g., in $\mathrm{kg}$ ) are converted into the equivalent data for chemostats (e.g., in $\mathrm{kg} / \mathrm{h}$ ) using the methods discussed in "Methods" section of Additional file 1.

The simulation of the entire process, including downstream separation; mass and energy balance calculations; and economic assessment, is all performed in SuperPro Designer [69] with built-in techno-economic parameters (see the specific values in Additional files 1 and 2). The split fractions calculated based on the discussed VLE calculation methods (see implementation in Additional file 2) are imported as fixed parameters into SuperPro to help specify the component flowrates after fermentation.

\section{Vapor-liquid equilibrium (VLE) analysis}

Limonene is liquid at the standard conditions, with a normal boiling point of $176{ }^{\circ} \mathrm{C}$. However, an interesting yet counterintuitive phenomenon is reported in many studies $[48,53,54,57,58,60,61,64,65]: 100 \%$ of limonene evaporates into the vapor phase after fermentation (operating at $\sim 30^{\circ} \mathrm{C}$ ). To understand this phenomenon, we first examine the vapor-liquid equilibrium of a general immiscible liquid mixture of Components 1 (e.g., limonene) and 2 (e.g., water) with inert gas (such as air) [70]. The system is shown in Fig. 2 and described by Eqs. 6-11, where $n_{1}, n_{2}$ and $n_{\text {gas }}$ are the total molar flowrates of 1, 2 and gas; $n_{1}^{\mathrm{V}}$ and $n_{2}^{V}$ are the molar flowrates of 1 and 2 in the vapor phase; $n_{1}^{\mathrm{L}}$ and $n_{2}^{\mathrm{L}}$ are the molar flowrates of 1 and 2 in the liquid phase. Further, we assume that the amount of gas dissolved in the liquid is negligible, which is a common assumption in such calculations; $T$ and $P$ are temperature and pressure; $P_{1}^{\mathrm{T}}, P_{2}^{\mathrm{T}}$ and $P_{\text {gas }}^{\mathrm{T}}$ are the partial vapor pressures of 1,2 and gas at temperature T; $P_{1}^{0}$ and $P_{2}^{0}$ are the vapor pressures of pure 1 and 2 at temperature $T$.

Equations 6 and 7 account for material balances.

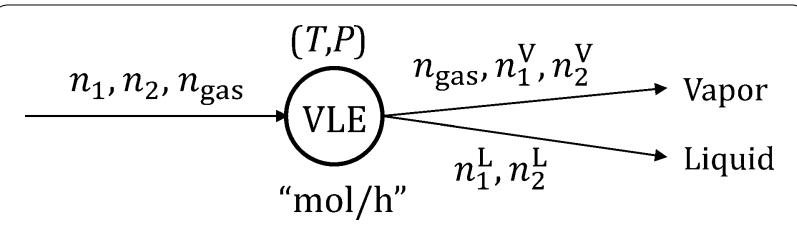

Fig. 2 VLE analysis of immiscible liquids with inert gas. The circle marked with "VLE" represents the VLE analysis module, i.e., Eqs. 6-11

$$
\begin{aligned}
& n_{1}^{\mathrm{V}}+n_{1}^{\mathrm{L}}=n_{1} \\
& n_{2}^{\mathrm{V}}+n_{2}^{\mathrm{L}}=n_{2}
\end{aligned}
$$

Equation 8 represents the ideal gas law.

$$
\frac{P_{\text {gas }}^{\mathrm{T}}}{n_{\text {gas }}}=\frac{P_{1}^{\mathrm{T}}}{n_{1}^{\mathrm{V}}}=\frac{P_{2}^{\mathrm{T}}}{n_{2}^{\mathrm{V}}}
$$

Equation 9 describes the partial vapor pressures of immiscible liquids, where the pressures are independent of the mixture concentration (unlike miscible liquids described by Raoult's law).

$$
P_{1}^{\mathrm{T}}=P_{1}^{0} ; P_{2}^{\mathrm{T}}=P_{2}^{0}
$$

Equation 10 describes the vapor pressures as functions, $f$ and $g$, of temperature through, for example, Antoine equation.

$$
P_{1}^{0}=f(T) ; P_{2}^{0}=g(T)
$$

Equation 11 represents Dalton's law.

$$
P_{1}^{\mathrm{T}}+P_{2}^{\mathrm{T}}+P_{\text {gas }}^{\mathrm{T}}=P
$$

Given $n_{1}, n_{2}, n_{\text {gas }}, T, P, f$ and $g$, we can solve Eqs. 6-11 to obtain $n_{1}^{\mathrm{V}}, n_{2}^{\mathrm{V}}, n_{1}^{\mathrm{L}}$, and $n_{2}^{\mathrm{L}}$, describing the distribution of Components 1 and 2 in the vapor and liquid phases. For example, for $n_{1}^{\mathrm{V}}$ we obtain

$$
n_{1}^{\mathrm{V}}=\frac{f(T) \times n_{\mathrm{gas}}}{P-f(T)-g(T)}
$$

Which monotonically increases with $n_{\text {gas }}$. However, note that based on this equation, $n_{\text {gas }}$ can be so large that $n_{1}^{\mathrm{V}}>n_{1}$ (and thus $n_{1}^{\mathrm{L}}<0$ based on Eq. 6), which is physically impossible. In fact, after $n_{\text {gas }}$ exceeds the threshold value where all of Component 1 is stripped to the vapor phase, $P_{1}^{\mathrm{T}}=P_{1}^{0}$ in Eq. 6 becomes invalid (because no liquid Component 1 exists any more). Accordingly, Eq. 12 no longer holds, and instead, $n_{1}^{\mathrm{V}}=n_{1}$ holds. A detailed explanation can be found in Figure S2 of Additional file 1 . Therefore, to account for systems where $n_{\text {gas }}$ exceeds the threshold value for Component 1 , we need to (1) remove $P_{1}^{\mathrm{T}}=P_{1}^{0}$ in Eq. 9, and (5) add $n_{1}^{\mathrm{V}}=n_{1}$. A similar 
argument holds for Component 2. Thus, variables $n_{1}^{\mathrm{V}}, n_{2}^{\mathrm{V}}$, $n_{1}^{\mathrm{L}}$ and $n_{2}^{\mathrm{L}}$ are obtained by accounting for $n_{\text {gas }}$ in its full range, as shown in Eqs. 13-16. The detailed derivation can be found in the "Results and discussion" section of Additional file 1.

$$
\begin{aligned}
& n_{1}^{\mathrm{V}}=\min \left(\frac{f(T) \times n_{\mathrm{gas}}}{P-f(T)-g(T)}, \frac{f(T) \times\left(n_{\mathrm{gas}}+n_{2}\right)}{P-f(T)}, n_{1}\right) \\
& n_{2}^{\mathrm{V}}=\min \left(\frac{g(T) \times n_{\mathrm{gas}}}{P-f(T)-g(T)}, \frac{g(T) \times\left(n_{\mathrm{gas}}+n_{1}\right)}{P-g(T)}, n_{2}\right) \\
& n_{1}^{\mathrm{L}}=n_{1}-\min \left(\frac{f(T) \times n_{\mathrm{gas}}}{P-f(T)-g(T)}, \frac{f(T) \times\left(n_{\mathrm{gas}}+n_{2}\right)}{P-f(T)}, n_{1}\right) \\
& n_{2}^{\mathrm{L}}=n_{2}-\min \left(\frac{g(T) \times n_{\mathrm{gas}}}{P-f(T)-g(T)}, \frac{g(T) \times\left(n_{\mathrm{gas}}+n_{1}\right)}{P-g(T)}, n_{2}\right)
\end{aligned}
$$

\section{VLE analysis in the fermenter}

Next, we apply the VLE analysis in the fermenter (Fig. 3). Essentially, through Eqs. 1-3, the raw materials (glucose, water and oxygen) are converted to a mixture of product, water, and gas (air and $\mathrm{CO}_{2}$ ) with flowrates $n_{\text {prod }}, n_{\text {water }}$, and $n_{\text {gas }}$, respectively. Based on Eqs. 13-16, we can identify the component flowrates in the vapor $\left(n_{\text {prod }}^{\mathrm{V}}\right.$ and $\left.n_{\text {water }}^{\mathrm{V}}\right)$ and liquid ( $n_{\text {prod }}^{\mathrm{L}}$ and $\left.n_{\text {water }}^{\mathrm{L}}\right)$. Specifically, we replace Components 1 and 2 with "product" and "water" and specify $T=30^{\circ} \mathrm{C}, P=1 \mathrm{~atm}$, as well as $f$ and $g$ (for limonene and water, respectively) in Eqs. $13-16$. We further relate $n_{\text {prod }}, n_{\text {water }}$, and $n_{\text {gas }}$ to the reactions in the fermenter and thus express them as functions of three easily comprehensible and controllable process parameters: (1) glucose concentration in the feed (wt\%), (2) yield (which can be expressed either as g product/g glucose, or \% of the maximum theoretical yield, i.e., $y \%$ in Eq. 2), and (3) $V V M\left(\mathrm{~min}^{-1}\right)$. The detailed deduction can be found in "Conclusions"

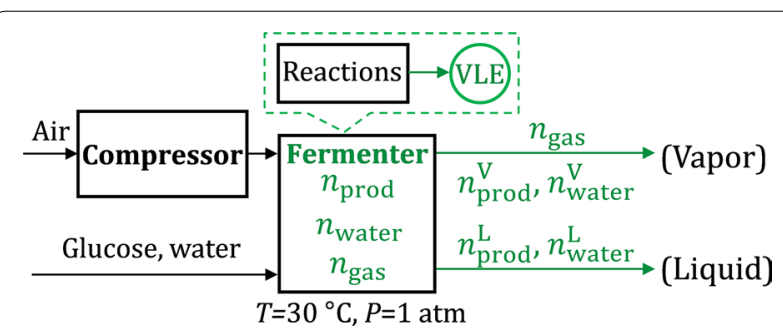

Fig. 3 VLE analysis applied in the fermenter. Parts related to the VLE analysis are marked in green section of Additional file 1. We find that these three parameters uniquely determine the system shown in Fig. 3.

Further, we calculate two variables that influence the downstream separation process: product split fraction to vapor $(\alpha)$ and liquid product titer $(\beta$, e.g., g/L), as shown in Eqs. 17 and 18, respectively.

$$
\alpha=\frac{n_{\text {prod }}^{\mathrm{V}}}{n_{\text {prod }}}
$$

$$
\beta=\frac{m_{\text {prod }}^{\mathrm{L}}}{Q^{\mathrm{L}}}
$$

where $m_{\text {prod }}^{\mathrm{L}}$ is the mass flowrate of product in the liquid phase and $Q^{\mathrm{L}}$ is the volumetric flowrate of the liquid phase. With further deduction ("Conclusions" section of Additional file 1), we find that $\alpha$ and $\beta$ are also functions of glucose concentration, yield and VVM.

\section{VLE analysis in the condenser}

Clearly, $\alpha$ will affect the downstream separations. If $\alpha$ is large (most product goes to the vapor phase after fermentation), we should first perform a condensation (assuming at $1 \mathrm{~atm}$ ) to convert the vapor product into liquid for further separation. To this end, as shown in Fig. 4, we perform VLE analysis in the condenser to identify $n_{\text {prod }}^{\mathrm{VV}}$ and $n_{\text {water }}^{\mathrm{VV}}$ in the vapor, $n_{\text {prod }}^{\mathrm{VL}}$ and $n_{\text {water }}^{\mathrm{VL}}$ in the condensed liquid, as well as the fraction of product condensed $(\lambda)$ and liquid product concentration after condensation $(\omega)$, as shown in Eqs. 19 and 20, respectively.

$$
\lambda=\frac{n_{\text {prod }}^{\mathrm{VL}}}{n_{\text {prod }}^{\mathrm{V}}}
$$

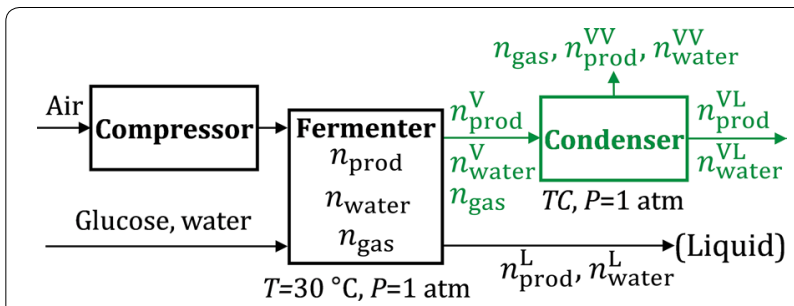

Fig. $4 \mathrm{VLE}$ analysis applied in the condenser. Parts related to the VLE analysis are marked in green. Note that $n_{\text {prod }}^{\vee}$ and $n_{\text {water }}^{\vee}$ can be calculated from the VLE analysis in the fermenter in Fig. 3 


$$
\omega=\frac{m_{\mathrm{prod}}^{\mathrm{VL}}}{Q^{\mathrm{VL}}}
$$

where $m_{\text {prod }}^{\mathrm{VL}}$ is the mass flowrate of product in the condensed liquid and $Q^{\mathrm{VL}}$ is the volumetric flowrate of the condensed liquid. With further deduction (Sect. 5 in Additional file 1), we find that $\lambda$ and $\omega$ are also functions of glucose concentration, yield and VVM.

To maximize product recovery, we operate the condenser such that $\lambda=100 \%$ (all the product is condensed), and the condenser temperature $T C$ can be calculated accordingly (see Sect. 5 of Additional file 1). For limonene, we calculate $\mathrm{TC} \cong 0{ }^{\circ} \mathrm{C}$.

\section{Case studies}

We apply the VLE analysis (in both the fermenter and condenser) on three case studies (see Table 2). Specifically, Case 1 is designed based on Willrodt et al.s data [61]. In Case 2, we assume glucose concentration and VVM values often reported in the literature, as well as a yield that may be achieved in the foreseeable future. Case 3 is designed based on the NREL study (optimistic case). Note that the $\mathrm{O}_{2}$ requirement is satisfied (with large enough VVM) in all three cases (see verifications in "Background" section of Additional file 1). Specifically, for the glucose concentration and yield values in Cases 1-3, $\mathrm{VVM}^{\mathrm{MIN}}=0.090,0.040$, and $0.0079 \mathrm{~min}^{-1}$, respectively.

Variables $\alpha, \beta$, and $\omega$ (at $\lambda=100 \%$ ) with varying VVM for the three cases are shown in Fig. 5. The specific parameters and calculations can be found in Additional files 1 and 2. Clearly, by increasing VVM, $\alpha$ increases while $\beta$ and $\omega$ decrease. Note that, based on the "Conclusions" section of Additional file 1, larger $\alpha$ will be achieved with lower glucose concentration, lower yield and higher VVM. For this reason, we note the following. First, $\alpha=100 \%$ (all the product goes to the vapor phase after fermentation) in Case 1 mainly due to very low yield, which explains the common experimental phenomenon that all the limonene ends up in the vapor phase. Second, $\alpha=35.1 \%$ in Case 2. Third, $\alpha=1.7 \%$ in Case 3

Table 2 Parameters assumed for the three case studies

\begin{tabular}{|c|c|c|c|c|c|}
\hline & $\begin{array}{l}\text { Glucose } \\
\text { concentration } \\
\text { (wt\%) }\end{array}$ & $\begin{array}{l}\text { Yield }(g \\
\text { product/g } \\
\text { glucose) }\end{array}$ & $\begin{array}{l}\text { Yielc } \\
\text { of } m\end{array}$ & $\begin{array}{l}\text { (6VM } \\
\left(\mathrm{min}^{-1}\right)\end{array}$ & $\begin{array}{l}\text { Residence } \\
\text { time (h) }\end{array}$ \\
\hline $\begin{array}{c}\text { Case } \\
1\end{array}$ & 14 & 0.00144 & 0.45 & 0.1 & 45 \\
\hline $\begin{array}{c}\text { Case } \\
2\end{array}$ & 10 & 0.122 & 38 & 0.1 & 45 \\
\hline $\begin{array}{c}\text { Case } \\
3\end{array}$ & 24 & 0.304 & 95 & 0.01 & 45 \\
\hline
\end{tabular}

due to high glucose concentration, high yield and low VVM.

\section{VLE implications on downstream separation}

While all the four process variables $(\alpha, \beta, \lambda$ and $\omega)$ influence separation cost, it is $\alpha$ that determines the suitable separation process configurations. The heat diagrams depicting the influence of glucose concentration and yield on $\alpha$ at different VVM values (1, 0.1 and $0.01 \mathrm{~min}^{-1}$ ) are shown in Fig. 6. The downstream separation process should be synthesized accordingly. Specifically, when $\alpha$ is very large (e.g., 99.9\%), only the product in the vapor phase after fermentation needs recovery, and thus a condenser is first used to condense the vapor stream (as discussed in "VLE analysis in condenser" section), followed by centrifugal decantation that separates the product (obtained as a top oil phase) from water. When $\alpha$ is very small (e.g., 1\%), all the product is practically in the liquid stream, so a direct centrifugal decantation suffices. Analyses based on several general bio-separation process synthesis methods [71-77], where different separation technologies are compared, also support the use of centrifugal decantation for this class of products. When $\alpha$ is neither very large nor very small, the product in both the vapor and liquid phases needs to be recovered.

\section{Results and discussion}

\section{Alternative process configurations}

The process configurations suitable for different $\alpha$ values are shown in Fig. 7. They also correspond to Cases 1-3 as examples. The liquid stream (S2), either with or without centrifugation, is recycled to save on water cost, and a $10 \%$ purge ratio is adopted to avoid accumulation of microbial cells. For the centrifugal decantation, we assume the limonene oil globule diameter to be $20 \mu \mathrm{m}$ [78]. It is used to calculate the rising velocity of limonene oil globules, which impacts the equipment size and electricity consumption. Finally, a $96 \mathrm{wt} \%$ limonene product stream is obtained after centrifugation. Key parameters and component flowrates are shown in Fig. 7. Other parameters for each unit can be found in Additional file 1. Also note the subtle trade-off between Configurations 1 and 2 when $\alpha$ is very large: sending the product in the liquid stream (S2) also to the centrifuge (as in Configuration 2) reduces product loss (compared with Configuration 1) but at the same time increases the centrifuge input flowrate (thus larger equipment and cost). Therefore, both configurations can be applicable in specific cases depending on the trade-off.

\section{Economic assessment of the case studies}

The costs for the three cases, by cost types, are summarized in Fig. 8. Both capital cost and operating costs, 

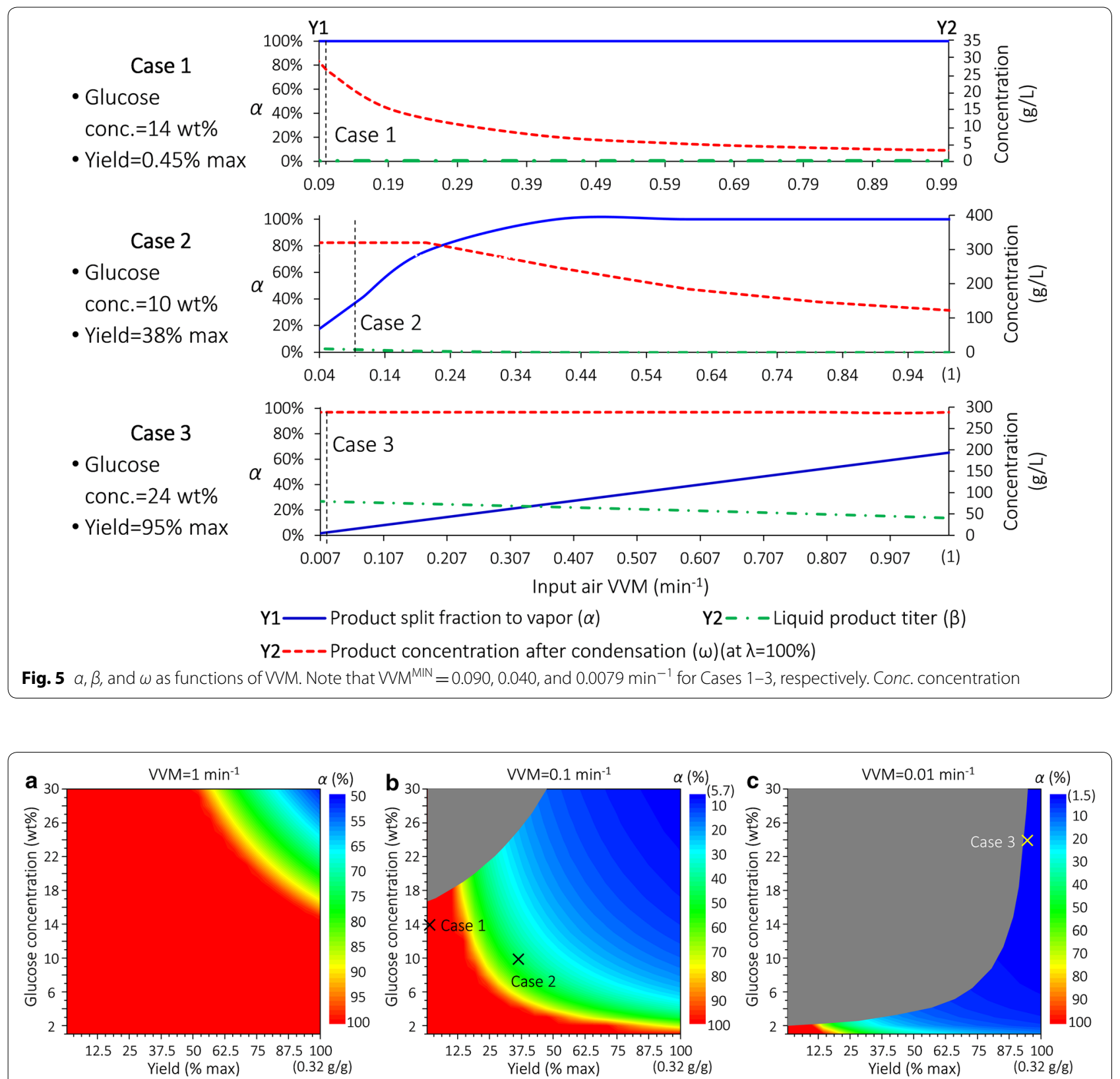

Fig. 6 Heat maps showing the influence of glucose concentration and yield on $a$ at different $\mathrm{VVM}$ values. $\mathbf{a} \mathrm{VWM}=1 \mathrm{~min}^{-1} ; \mathbf{b} \mathrm{VVM}=0.1 \mathrm{~min}^{-1} ; \mathbf{c}$ $\mathrm{VM}=0.01 \mathrm{~min}^{-1}$. The numbers in parentheses on the color scales in $\mathbf{b}$ and $\mathbf{c}$ denote the corresponding minimum a values. Gray-shaded areas represent infeasible regions where $\mathrm{VVM}<\mathrm{VVM}^{\mathrm{MIN}}$ (calculated using the method discussed in "Bio-conversion process" section)

including costs of feedstock, utility, and other (labor and miscellaneous), are included. Costs by units are summarized in Sect. 6 of Additional file 1. The total unit production costs for the three cases are $465,5.82$, and $2.02 \$ / \mathrm{kg}$ limonene, respectively. Feedstock is the major cost component in all cases. In comparison, lower cost is achieved with a higher glucose concentration (thus smaller equipment size and therefore lower capital and utility costs), a higher yield (thus high product flowrate and therefore lower unit production cost), and a lower VVM (thus cheaper air compression).

Unlike many other bio-based chemical production processes, where separation accounts for $60-80 \%$ of the total cost $[13,79]$, separation is not the major cost driver here mainly because limonene (and most other terpenes) is extracellular, insoluble, and lighter than water (in terms of density), which requires a simple centrifugal decantation. Note that the separation cost will increase when 

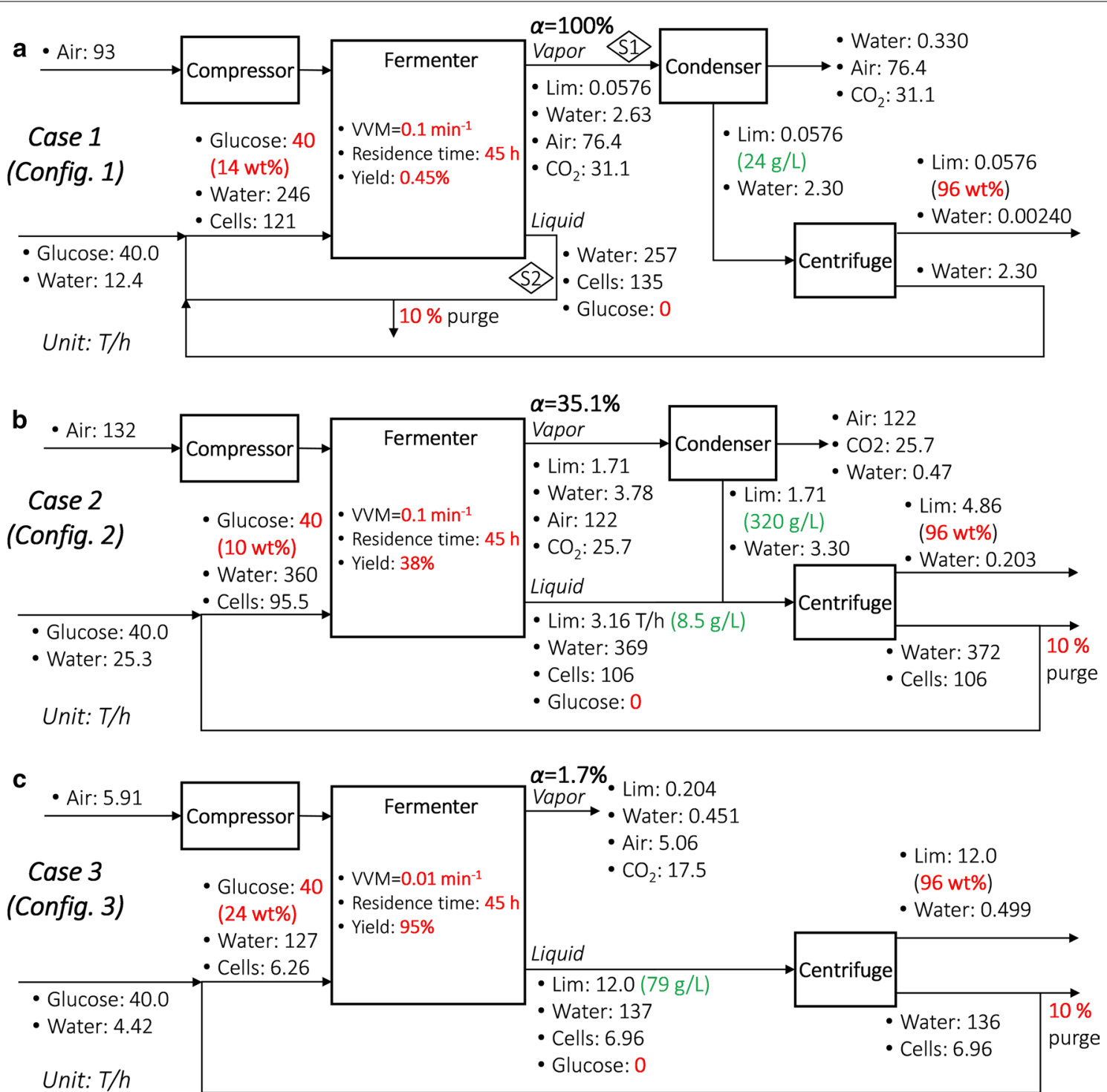

Fig. 7 Three process configurations. a Configuration 1 (e.g., Case 1), where the product is mainly in the vapor; b Configuration 2 (e.g., Case 2), where the product is distributed in the vapor and liquid; c Configuration 3 (e.g., Case 3), where the product is mainly in the liquid. Given parameters for each case are marked bold in red. Lim limonene. For the component flowrates in each stream, the units are T/h, and three significant figures are kept. Product concentrations in specific streams are marked in green

a product's oil globule size is smaller and the density is closer to that of water (based on Stokes's law), which can lead to a smaller globule rising velocity in the decanter and thus larger equipment. For example, if we consider a terpene with globule diameter $1 \mu \mathrm{m}$ and density $950 \mathrm{~g} / \mathrm{L}$, instead of limonene $(20 \mu \mathrm{m}$ and $841 \mathrm{~g} / \mathrm{L})$, then the centrifugation cost in Case 3 will increase by $40 \%$ (although the total cost will increase by just $0.1 \%$ due to high feed glucose cost).

To compare configurations under different glucose concentration, yield, and VVM, we generate Fig. 9, where the optimal configurations are labeled in the corresponding regions. In general, Configuration 2 is a low-cost option, but under specific conditions, the other configurations can have lower costs.

\section{General economic assessment}

To identify the cost-minimal process configuration and the corresponding cost, for any case, we can perform economic assessment assuming that all the three configurations can be used and then choose the one with the minimum cost. We perform such analysis for various glucose concentration and yield combinations under three VVM values $\left(1,0.1\right.$, and $\left.0.01 \mathrm{~min}^{-1}\right)$, as represented 


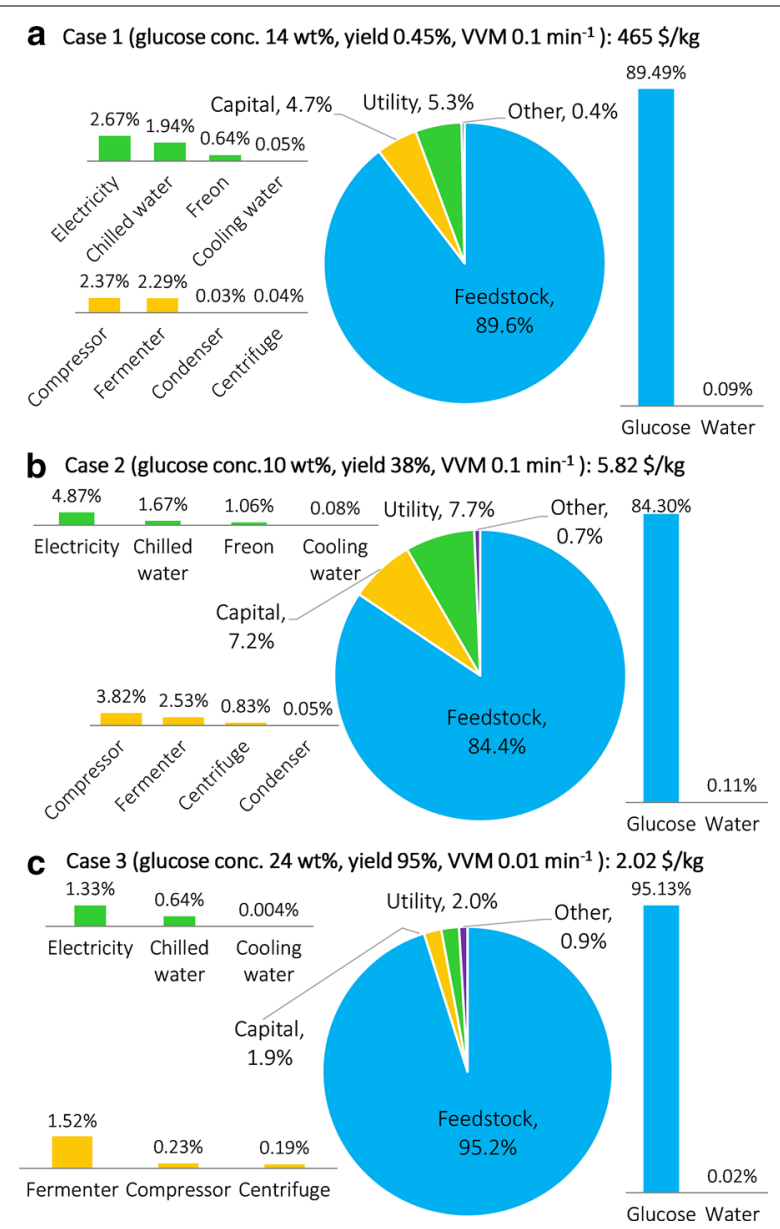

Fig. 8 Cost distribution by cost types. a Case 1; b Case 2; $\mathbf{c}$ Case 3 Capital costs are annualized

in the "heat maps" in Fig. 10a-c, respectively. The color scales represent the minimum unit production costs, and the optimal process configurations are marked accordingly in the different regions separated by the white contour curves. Gray-shaded areas represent infeasible regions where $\mathrm{VVM}<\mathrm{VVM}^{\mathrm{MIN}}$. Clearly, Configuration 1 is optimal at relatively high VVM, low glucose concentration, and low yield (rendering high cost); Configuration 3 is optimal at relatively low VVM, high glucose concentration, and high yield (rendering low cost); Configuration 2 is optimal in between. The cost-price break-even cases (cost $=7 \$ / \mathrm{kg}$ ) are also shown, marked with red dashed curves. Also note that we present yield up to $100 \%$, but $50 \%$ is likely a reasonable target in the foreseeable future.

It is also worth noting that evaporation of limonene actually generates a more concentrated product stream after condensation (e.g., $26 \mathrm{~g} / \mathrm{L}$ after condensation vs. $0.22 \mathrm{~g} / \mathrm{L}$ assuming no evaporation in the fermenter in Case 1; see Fig. 7a), which facilitates downstream separation. However, we should not increase VVM to "push" more product to the vapor phase, because a higher VVM for each glucose concentration and yield combination in Fig. 10 leads to a higher cost. In other words, the additional costs of compression and condensation due to increased VVM outweigh the savings from separation (centrifugal decantation).

\section{Addressing toxicity: use of solvent vs. microbial engineering}

Some terpenes like limonene are, in fact, toxic to microbes, which prevents product titer from reaching a high level. There are currently two major methods to address this challenge: (1) engineering of the microbes to increase resilience, and (2) biphasic fermentation, including air stripping of the product and the use of a solvent miscible with the product (and immiscible with water) to reduce terpene concentration in the aqueous phase, where the microbes exist [40]. The first method has been assumed in our discussions so far when Configurations 2 and 3 are used, thus allowing the product yield to reach a high level. Also, using a chemostat helps further alleviate the problem because products and microbes are constantly withdrawn from the fermenter. In the second method, air stripping is used in Configuration 1, where the product flows to the vapor phase while the microbes stay in the liquid phase. The use of solvent (such as dodecane, commonly used for limonene) can reduce terpene concentration in the aqueous phase, while simultaneously preventing evaporation [40, 48, 61]. Also, the use of solvent can potentially help remove any additional impurities due to the lysis of cells. We develop a process based on such solvent-based separation (Configuration 4). It is demonstrated using Case 4 as shown in Fig. 11a.

Specifically, we adopt the parameters from Case 3 (glucose concentration $=24 \mathrm{wt} \%$, yield $=95 \%$, and $\mathrm{VVM}=0.01 \mathrm{~min}^{-1}$ ) and add dodecane as a solvent (miscible with limonene and immiscible with water) into the fermenter. Since dodecane prevents evaporation, only the liquid stream is treated with centrifugal decantation. The limonene-dodecane mixture is then distilled to obtain the final product, while dodecane is recycled. In terms of the amount of dodecane used, values between 5 and $20 \mathrm{vol} \%$ are reported in the literature [54, 60, 80, 81]. We assume 10 vol\% here.

The total cost is $2.16 \$ / \mathrm{kg}$, as shown in Fig. 11b. Costs by units are summarized in Sect. 7 of Additional file 1 . Cost comparisons with the non-solvent scenario (microbial engineering) under glucose concentration $=24 \mathrm{wt} \%$ and $\mathrm{VVM}=0.01$ and $0.1 \mathrm{~min}^{-1}$, respectively, are shown in Fig. 12a, b. When VVM $=0.01 \mathrm{~min}^{-1}$, Configuration 4 is $\sim 0.14 \$ / \mathrm{kg}$ (7\%) more expensive than Configuration 3 (the optimal configuration assuming no use of solvent); when $\mathrm{VVM}=0.1 \mathrm{~min}^{-1}$, Configuration 4 is $0.08-6.48$ 

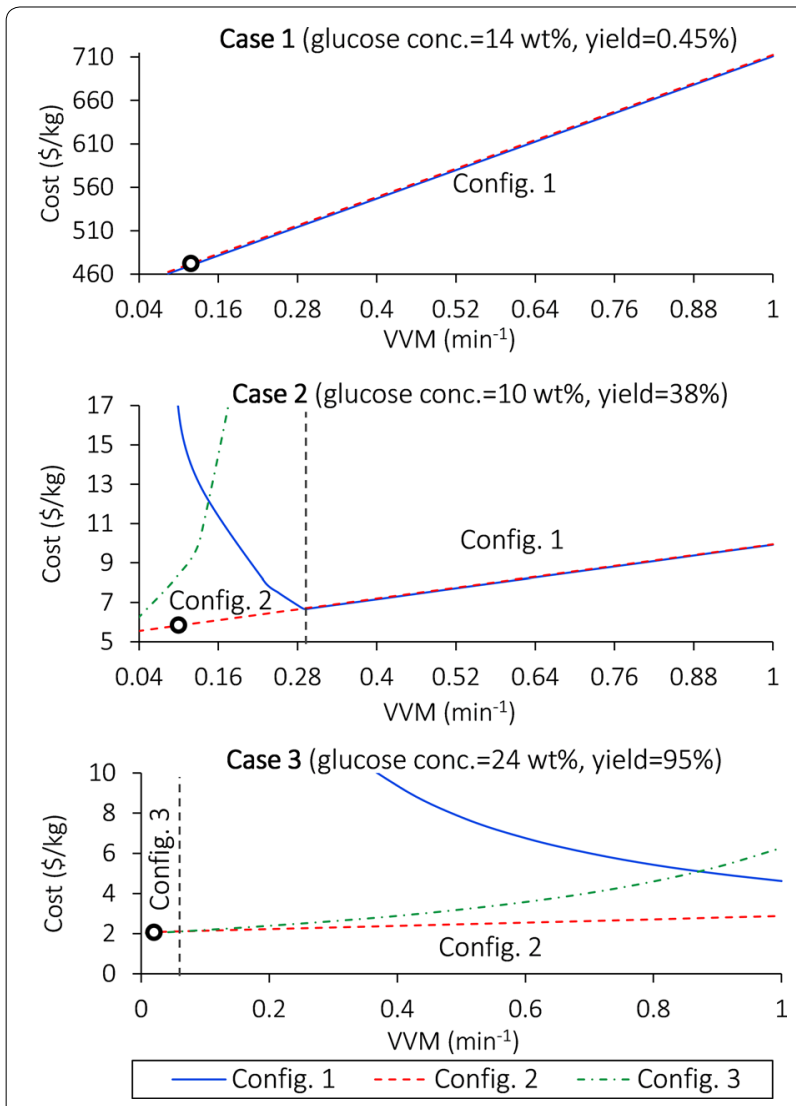

Fig. 9 Cost comparison between configurations with varying WVM values in different cases. The vertical dashed lines denote threshold VVM values where the cost-minimal configurations change; the optimal configurations are labeled in the corresponding regions. The three cases are represented by the small circles. Note that $V_{V M}{ }^{\mathrm{MIN}}=0.090,0.040$, and $0.0079 \mathrm{~min}^{-1}$ for Cases $1-3$, respectively

$\$ / \mathrm{kg}$ (4-6\%) more expensive than Configuration 2 (optimal).

\section{Extensions}

The method presented in this work can be used to study systems producing different terpenes (by modifying Eq. 2 and product physical properties accordingly), as well as different microbes (by modifying Eq. 1) and bio-conversion systems (by replacing the fermenter with, for example, an open pond, and glucose with $\mathrm{CO}_{2}$ to account for photosynthesis instead of fermentation).

We study production systems for different terpenes using the assumptions for Case 3 (glucose concentration $=24 \mathrm{wt} \%$, yield $=95 \%, \mathrm{VVM}=0.01 \mathrm{~min}^{-1}$ ). Cost estimates along with the expected annual profit assuming 100\% market share for all the terpenes in Table 1 using the methods discussed in this work are presented in Table 3. Also, the break-even yield for Configurations $1-3$ is calculated for each product, assuming Case

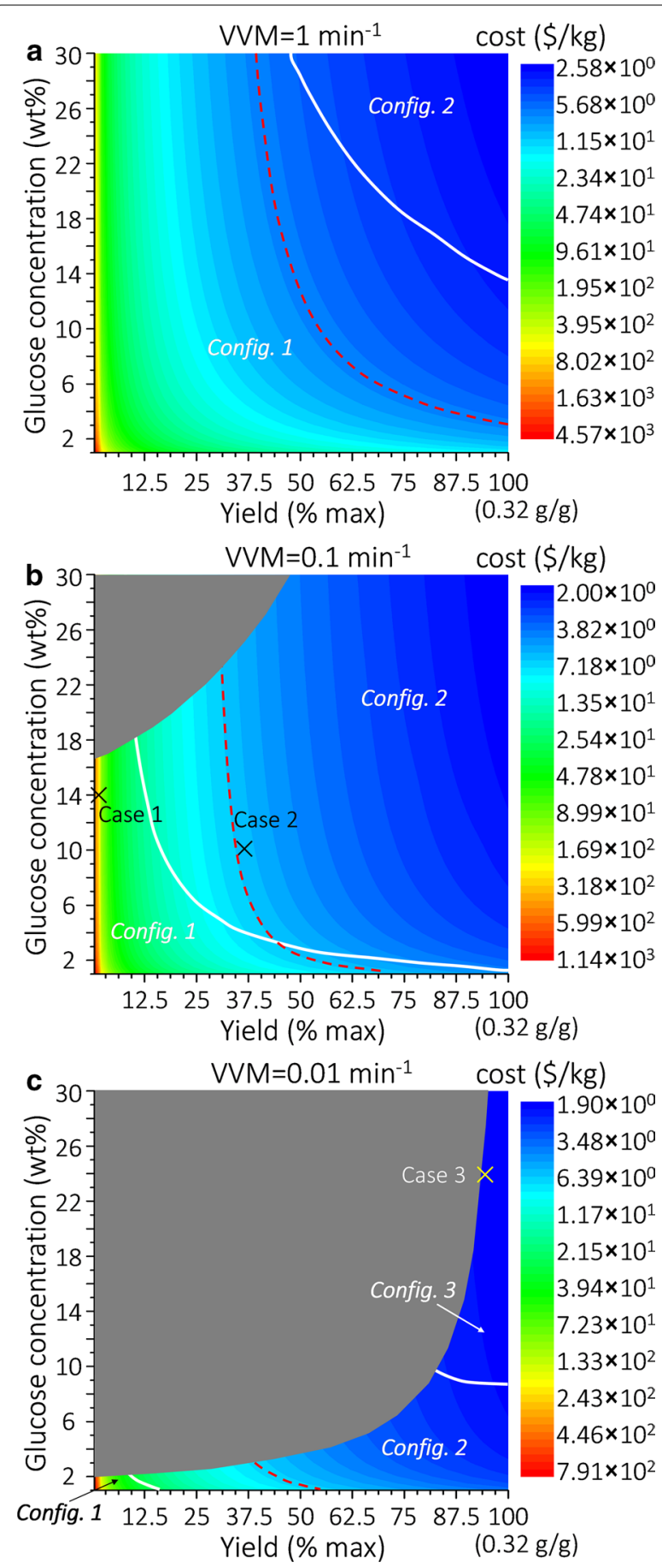

Fig. 10 Heat maps depicting the influence of glucose concentration and yield on configurations and costs. $\mathbf{a} \mathrm{VVM}=1 \mathrm{~min}^{-1} ; \mathbf{b}$ $\mathrm{VVM}=0.1 \mathrm{~min}^{-1} ; \mathbf{c} V \mathrm{VM}=0.01 \mathrm{~min}^{-1}$. The color scales are plotted logarithmically. The white solid contour curves denote the boundaries where the optimal process configurations change. The red dashed curves denote break-even combinations of glucose concentration and yield. Gray-shaded areas represent infeasible regions where $\mathrm{VMM}<\mathrm{VVM}^{\mathrm{MIN}}$. Note that $50 \%$ yield is likely a reasonable target in the foreseeable future 


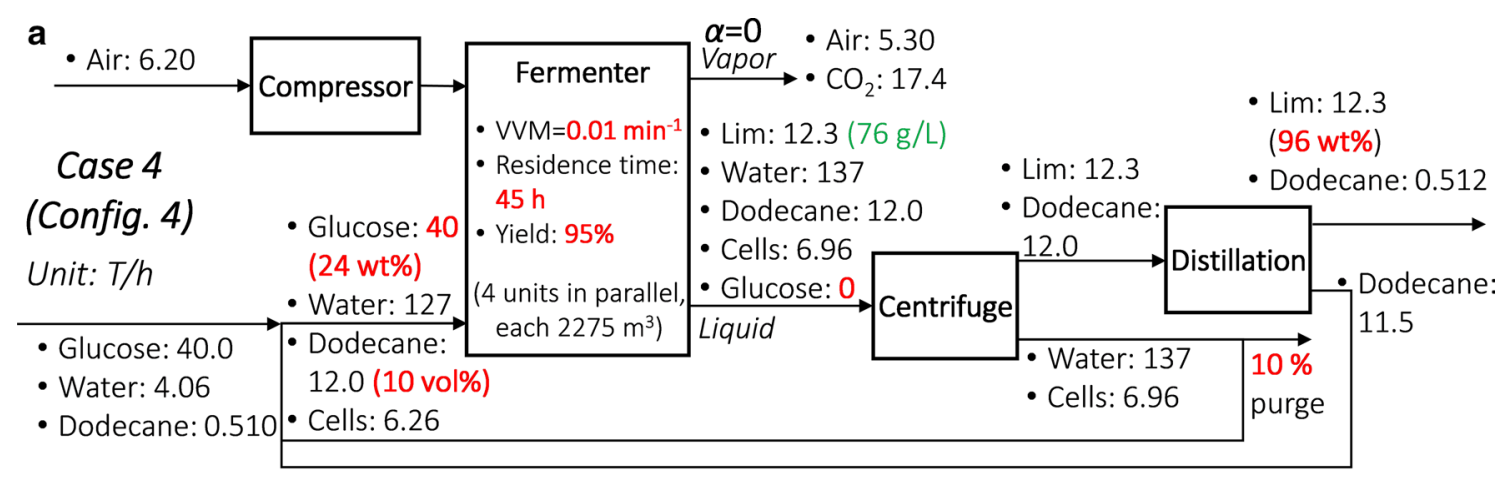

b

Total cost: $2.16 \$ / \mathrm{kg}$
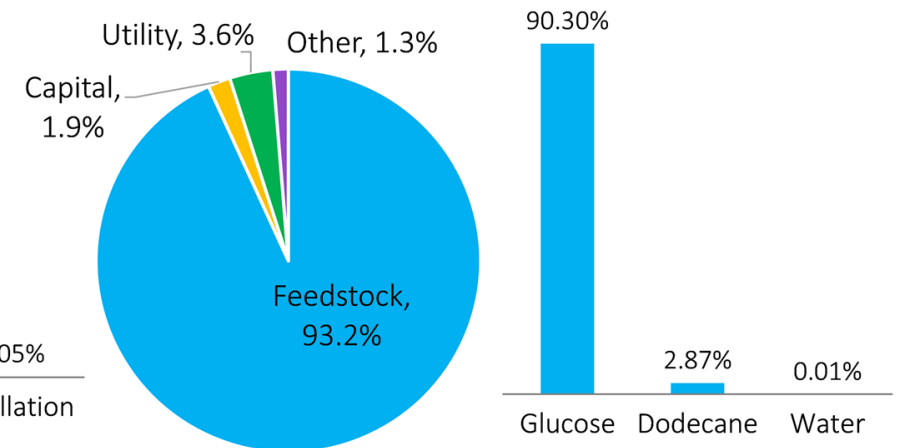

Fig. 11 Process configuration and economic assessment of Case 4. a Process Configuration 4; b cost distribution

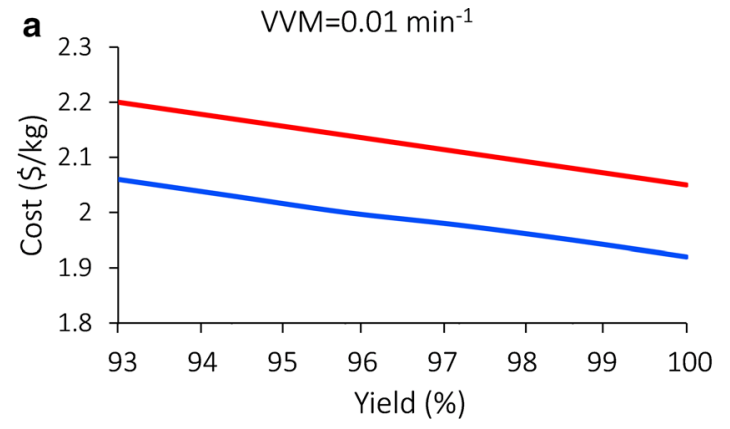

Config. 3 (optimal) Config. 4

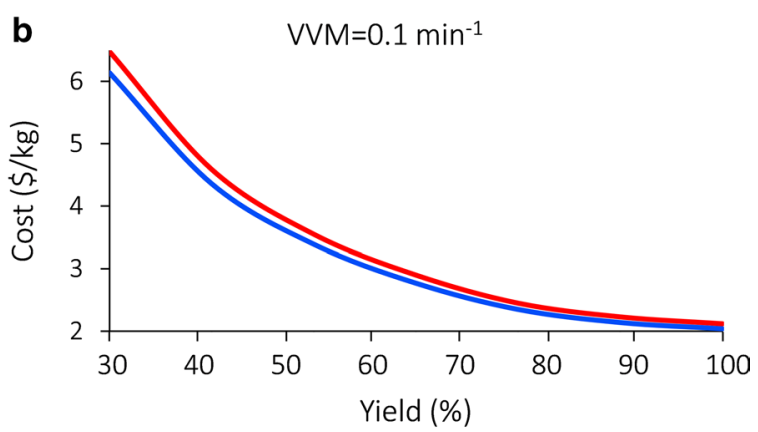

Config. 2 (optimal) -Config. 4

Fig. 12 Cost comparison between Configuration 4 and the non-solvent configuration. a Glucose concentration $=24$ wt $\%$ and WVM=0.01 $\mathrm{min}^{-1} ; \mathbf{b}$ glucose concentration $=24 \mathrm{wt} \%$ and $\mathrm{VVM}=0.1 \mathrm{~min}^{-1}$. Only the yield ranges that satisfy $\mathrm{VVM}>\mathrm{VVM}{ }^{\mathrm{MIN}}$ are shown

1 glucose concentration (14 wt\%) and VVM $\left(0.1 \mathrm{~min}^{-1}\right)$. The minimum break-even yield, across configurations, and the corresponding optimal configuration are shown in Table 4.

Limonene appears to be the most promising shortterm target because it has a comparatively high expected profit based on our current assumptions (Table 3), as well as a relatively low break-even yield (Table 4). For the terpenes with high prices yet low market volumes, the break-even yields are even easier to achieve, but the total market size is small. More accurate market volume data are needed to better quantify their economic prospect. Also, low-volume products are often used for niche markets (e.g., cosmetics and pharmaceuticals), which have much stricter final product requirements, and thus their actual costs may be underestimated here.

In addition, if cellulosic biomass, instead of pure glucose, can be used as the feedstock (as in the NREL process), then the process before fermentation includes biomass pre-treatment and enzymatic hydrolysis [66]. The stream after hydrolysis contains $240 \mathrm{~g} / \mathrm{L}$ sugar, and the cost of pre-treatment and hydrolysis is $\sim 0.28 \$ / \mathrm{kg}$ 
Table 3 Minimum break-even yields and the corresponding optimal process configurations for 12 terpenes

\begin{tabular}{lll}
\hline Terpene & $\begin{array}{l}\text { Minimum break-even yield } \\
\text { (\% max.) }\end{array}$ & $\begin{array}{l}\text { Optimal } \\
\text { configuration }\end{array}$ \\
\hline Isoprene & NA & NA \\
D-Limonene & 30 & 2 \\
B-Pinene & 42 & 2 \\
a-Pinene & 85 & 2 \\
Linalool & 41 & 2 \\
Squalene & 5.9 & 3 \\
Y-Bisabolene & 1.2 & 3 \\
Lycopene & 1.9 & 3 \\
a-Humulene & 4.0 & 3 \\
Valencene & 4.0 & 3 \\
3-Carene & 4.7 & 1 \\
Y-Terpinene & 5.9 & 2 \\
\hline
\end{tabular}

Glucose concentration $=24 \mathrm{wt} \%$, yield $=95 \%, \mathrm{VVM}=0.01 \mathrm{~min}^{-1}$

Table 4 Minimum break-even yields and the corresponding optimal process configurations for 12 terpenes

\begin{tabular}{lll}
\hline Terpene & $\begin{array}{l}\text { Minimum break-even yield } \\
\text { (\% max.) }\end{array}$ & $\begin{array}{l}\text { Optimal } \\
\text { configuration }\end{array}$ \\
\hline Isoprene & NA & NA \\
D-Limonene & 30 & 2 \\
B-Pinene & 42 & 2 \\
a-Pinene & 85 & 2 \\
Linalool & 41 & 2 \\
Squalene & 5.9 & 3 \\
Y-Bisabolene & 1.2 & 3 \\
Lycopene & 1.9 & 3 \\
a-Humulene & 4.0 & 3 \\
Valencene & 4.0 & 3 \\
3-Carene & 4.7 & 1 \\
Y-Terpinene & 5.9 & 2 \\
\hline
\end{tabular}

Glucose concentration $=14 \mathrm{wt} \%$ and VVM $=0.1 \mathrm{~min}^{-1}$ are assumed

(pure sugar basis), i.e., a 53\% feedstock cost saving compared to the $0.6 \$ / \mathrm{kg}$ pure glucose price. We do not consider the use of cellulosic biomass in this study due to its limited applications in industry. Nonetheless, the readers can account for this technology by reducing the current glucose cost by $53 \%$.

Note that this work is intended to be a high-level synthesis and analysis of bio-based terpene processes. Our goal is to identify the key cost drivers and provide target values for the researchers working in the area. If the key parameters discussed herein are substantially improved in the future, so that a positive profit margin can potentially be achieved, then more detailed studies accounting for aspects such as contamination prevention and microbial cell growth control would be required.

Finally, we note that the approaches discussed in this work can be used to study processes for the production of other extracellular, insoluble, and light (in terms of density compared to water) products, such as fatty acids.

\section{Conclusions}

This work focuses on the process synthesis, simulation, and techno-economic evaluation of microbial terpenes production. We first analyzed the vapor-liquid equilibrium, which explained the counterintuitive experimental phenomenon where terpenes such as limonene (normal boiling point $176{ }^{\circ} \mathrm{C}$ ) are often found to be $100 \%$ present in the vapor phase after fermentation (at $\sim 30{ }^{\circ} \mathrm{C}$ ). Based on this analysis, we further proposed three alternative process configurations, demonstrated with three different case studies.

We estimated that the total unit production costs of the three cases are 465, 5.82, and $2.02 \$ / \mathrm{kg}$, respectively. We also identified the key cost drivers to be (1) feed glucose concentration, (2) yield, and (3) VVM. We further showed how these drivers impact costs and the selectin of the corresponding configurations. We found that the production of limonene, based on current literature experimental data, is economically infeasible and that higher glucose concentration and yield are key to lowering the cost.

Finally, we extended the assessment to account for different process parameters, terpene products, strategies to address terpene toxicity (microbial engineering vs. use of solvent), and cellulosic biomass as a feedstock. After studying the economics of 12 terpenes, limonene appears to be the most reasonable short-term target.

The framework and suite of methods presented herein are applicable to a wide range of extracellular insoluble chemicals with density lower than that of water, such as fatty acids. Therefore, the proposed methods can provide guidance and useful insights into the development of bio-based production systems for terpenes and other bioproducts.

\section{Additional files}

Additional file 1. Additional calculations and details of the analyses.

Additional file 2. Editable Excel file containing (1) assumptions for TEA, (2) VLE calculations, and (3) Figures.

Authors' contributions

WW performed the VLE analysis, process synthesis, techno-economic assessment, and completed the writing of the manuscript. CTM supervised the 
work, provided research directions and resources, and provided feedback on writing. Both authors read and approved the final manuscript.

\section{Acknowledgements}

We thank Profs Brian F. Pfleger and Jennifer L. Reed and Nestor J. Hernandez Lozada for fruitful discussions on terpene production and bio-conversions.

\section{Competing interests}

The authors declare that they have no competing interests.

\section{Availability of data and materials}

Data generated or analyzed during this study are included in this published article and its additional files. Additional information is available from the corresponding author on reasonable request.

\section{Consent for publication}

Not applicable.

\section{Ethics approval and consent to participate}

Not applicable.

\section{Funding}

This work was funded by National Science Foundation through the Emerging Frontiers in Research and Innovation program (EFRI-1240268), and the DOE Great Lakes Bioenergy Research Center (DOE BER Office of Science DE-SC0018409).

\section{Publisher's Note}

Springer Nature remains neutral with regard to jurisdictional claims in published maps and institutional affiliations.

Received: 1 May 2018 Accepted: 9 October 2018

Published online: 27 October 2018

\section{References}

1. Bordbar A, Monk JM, King ZA, Palsson BO. Constraint-based models predict metabolic and associated cellular functions. Nat Rev Genet. 2014;15(2):107-20.

2. Feist AM, Palsson BO. The biomass objective function. Curr Opin Microbiol. 2010;13(3):344-9.

3. Woolston BM, Edgar S, Stephanopoulos G. Metabolic engineering: past and future. Annu Rev Chem Biomol Eng. 2013;4(1):259-88.

4. Yadav VG, De Mey M, Giaw Lim C, Kumaran Ajikumar P, Stephanopoulos $\mathrm{G}$. The future of metabolic engineering and synthetic biology: towards a systematic practice. Metab Eng. 2012;14(3):233-41.

5. de Jong E, Higson A, Walsh P, Wellisch M. Bio-based chemicals_value added products from biorefineries. IEA Bioenergy, Task42 Biorefinery, 2012. p. 34.

6. Jang YS, Kim B, Shin JH, Choi YJ, Choi S, Song CW, Lee J, Park HG, Lee SY. Bio-based production of C2-C6 platform chemicals. Biotechnol Bioeng. 2012;109(10):2437-59.

7. Jullesson D, David F, Pfleger B, Nielsen J. Impact of synthetic biology and metabolic engineering on industrial production of fine chemicals. Biotechnol Adv. 2015;33(7):1395-402.

8. Lanza AM, Crook NC, Alper HS. Innovation at the intersection of synthetic and systems biology. Curr Opin Biotechnol. 2012;23(5):712-7.

9. Miskovic L, Hatzimanikatis V. Production of biofuels and biochemicals: in need of an ORACLE. Trends Biotechnol. 2010;28(8):391-7.

10. Nicolaou SA, Gaida SM, Papoutsakis ET. A comparative view of metabolite and substrate stress and tolerance in microbial bioprocessing: from biofuels and chemicals, to biocatalysis and bioremediation. Metab Eng. 2010;12(4):307-31.

11. Bornscheuer UT, Nielsen AT. Editorial overview: chemical biotechnology: interdisciplinary concepts for modern biotechnological production of biochemicals and biofuels. Curr Opin Biotechnol. 2015;35:133-4
12. Nielsen J, Fussenegger M, Keasling J, Lee SY, Liao JC, Prather K, Palsson B. Engineering synergy in biotechnology. Nat Chem Biol. 2014;10(5):319-22

13. Kiss AA, Grievink J, Rito-Palomares M. A systems engineering perspective on process integration in industrial biotechnology. J Chem Technol Biotechnol. 2015;90(3):349-55.

14. Kirby J, Keasling JD. Biosynthesis of plant isoprenoids: perspectives for microbial engineering. Annu Rev Plant Biol. 2009;60(1):335-55.

15. Zebec Z, Wilkes J, Jervis AJ, Scrutton NS, Takano E, Breitling R. Towards synthesis of monoterpenes and derivatives using synthetic biology. Curr Opin Chem Biol. 2016;34:37-43.

16. Katherine RS. Monoterpene biotransformation by the yeast. Indo Am J Pharm Res. 2016;6(02):2-6.

17. Wang S, Zhang S, Xiao A, Rasmussen M, Skidmore C, Zhan J. Metabolic engineering of Escherichia coli for the biosynthesis of various phenylpropanoid derivatives. Metab Eng. 2015;29(1):153-9.

18. Augustin JM, Kuzina V, Andersen SB, Bak S. Molecular activities, biosynthesis and evolution of triterpenoid saponins. Phytochemistry. 2011;72(6):435-57.

19. Thimmappa R, Geisler K, Louveau T, O'Maille P, Osbourn A. Triterpene biosynthesis in plants. Annu Rev Plant Biol. 2014;65(1):225-57.

20. Gershenzon J, Dudareva N. The function of terpene natural products in the natural world. Nat Chem Biol. 2007;3(7):408-14.

21. Chandran SS, Kealey JT, Reeves CD. Microbial production of isoprenoids. Process Biochem. 2011;46(9):1703-10.

22. Kirby J, Keasling JD. Metabolic engineering of microorganisms for isoprenoid production. Nat Prod Rep. 2008;25(4):656.

23. Maury J, Asadollahi MA, Møller K, Clark A, Nielsen J. Microbial isoprenoid production: an example of green chemistry through metabolic engineering. In: Nielsen J, editor. Biotechnology for the future. Berlin: Springer; 2005. p. 19-51.

24. Ciriminna R, Lomeli-Rodriguez M, Demma Carà P, Lopez-Sanchez JA, Pagliaro M. Limonene: a versatile chemical of the bioeconomy. Chem Commun. 2014;50(97):15288-96.

25. Johnson TJ, Jahandideh A, Johnson MD, Fields KAH, Richardson JW, Muthukumarappan K, Cao Y, Gu ZR, Halfmann C, Zhou R, Gibbons WR. Producing next-generation biofuels from filamentous cyanobacteria: an economic feasibility analysis. Algal Res. 2016;20:218-28.

26. Halfmann C, Gu L, Zhou R. Engineering cyanobacteria for the production of a cyclic hydrocarbon fuel from $\mathrm{CO}_{2}$ and $\mathrm{H}_{2} \mathrm{O}$. Green Chem. 2014;16(6):3175-85.

27. Chang MCY, Eachus RA, Trieu W, Ro DK, Keasling JD. Engineering Escherichia coli for production of functionalized terpenoids using plant P450s. Nat Chem Biol. 2007;3(5):274-7.

28. Wendler DS. Problems with the consensus definition of the therapeutic misconception. J Clin Ethics. 2013;24(4):387-94.

29. Kampranis SC, Makris AM. Developing a yeast cell factory for the production of terpenoids. Comput Struct Biotechnol J. 2012;3(4):e201210006.

30. Martin VJJ, Piteral DJ, Withers ST, Newman JD, Keasling JD. Engineering a mevalonate pathway in Escherichia coli for production of terpenoids. Nat Biotechnol. 2003;21(7):796-802.

31. Morrone D, Lowry L, Determan MK, Hershey DM, Xu M, Peters RJ. Increasing diterpene yield with a modular metabolic engineering system in $E$. coli: comparison of MEV and MEP isoprenoid precursor pathway engineering. Appl Microbiol Biotechnol. 2010;85(6):1893-906.

32. Peralta-Yahya PP, Ouellet M, Chan R, Mukhopadhyay A, Keasling JD, Lee TS. Identification and microbial production of a terpene-based advanced biofuel. Nat Commun. 2011;2(1):483.

33. Vickers CE, Bongers M, Liu Q, Delatte T, Bouwmeester H. Metabolic engineering of volatile isoprenoids in plants and microbes. Plant Cell Environ. 2014;37(8):1753-75.

34. Wang X, Ort DR, Yuan JS. Photosynthetic terpene hydrocarbon production for fuels and chemicals. Plant Biotechnol J. 2015;13(2):137-46.

35. Zhuang $X$. Engineering novel terpene production platforms in the yeast saccharomyces cerevisiae. Diss Plant Soil Sci Pap. 2013;17:1-189.

36. Yamada Y, Kuzuyama T, Komatsu M, Shin-ya K, Omura S, Cane DE, Ikeda H. Terpene synthases are widely distributed in bacteria. Proc Natl Acad Sci. 2015;112(3):857-62.

37. Cuellar MC, van der Wielen LAM. Recent advances in the microbial production and recovery of apolar molecules. Curr Opin Biotechnol. 2015;33:39-45. 
38. Heeres AS, Picone CSF, van der Wielen LAM, Cunha RL, Cuellar MC. Microbial advanced biofuels production: overcoming emulsification challenges for large-scale operation. Trends Biotechnol. 2014;32(4):221-9.

39. Heeres A, Cuellar M, Van der Wielen L. Integrated fermentation and separation for the production of advanced biofuels. In: 36th symposium on biotechnology for fuels and chemicals. 2014.

40. Schrader J, Bohlmann J. Biotechnology of isoprenoids. 2015;148:114.

41. Wu W, Long MR, Zhang X, Reed JL, Maravelias CT. A framework for the identification of promising bio-based chemicals. Biotechnol Bioeng. 2018;115:2328-40.

42. Lohrasbi M, Pourbafrani M, Niklasson C, Taherzadeh MJ. Process design and economic analysis of a citrus waste biorefinery with biofuels and limonene as products. Bioresour Technol. 2010;101(19):7382-8.

43. Pourbafrani M, Forgács G, Horváth IS, Niklasson C, Taherzadeh MJ. Production of biofuels, limonene and pectin from citrus wastes. Bioresour Technol. 2010;101(11):4246-50.

44. Pourbafrani M. Citrus waste biorefinery: process development, simulation and economic analysis department of chemical and biological engineering. 2010.

45. Hodges AW, Rahmani M, Stevens TJ, Spreen TH. Economic impacts of the florida citrus industry in 2012-2013. 2014:1-39.

46. Wikandari R, Nguyen H, Millati R, Niklasson C, Taherzadeh MJ. Improvement of biogas production from orange peel waste by leaching of limonene. Biomed Res Int. 2015;2015:1-6.

47. Pace G, Righelato R. Production of extracellular microbial polysaccharides. Adv. Biochem. Eng. 1980;15:41-70.

48. Jongedijk E, Cankar K, Buchhaupt M, Schrader J, Bouwmeester H, Beekwilder J. Biotechnological production of limonene in microorganisms. Appl Microbiol Biotechnol. 2016;100(7):2927-38.

49. ICIS. Icis Chemical Business, 1, 4. 2016. https://www.icis.com/. Accessed 15 Mar 2018.

50. USEPA. Chemical Data Access Tool (CDAT). 2013. https://java.epa.gov/ oppt_chemical_search/. Accessed 15 Mar 2018.

51. USEPA. 2006 lur. 2006. https://www.epa.gov/chemical-data-reporting/ downloadable-2006-iur-public-database. Accessed 5 Jan 2018.

52. Mukhopadhyay A. Tolerance engineering in bacteria for the production of advanced biofuels and chemicals. Trends Microbiol. 2015:23(8):498-508

53. Bicas JL, Pastore GM. Isolation and screening of D-limonene-resistant microorganisms. Braz J Microbiol. 2007;38(3):563-7.

54. Alonso-Gutierrez J, Chan R, Batth TS, Adams PD, Keasling JD, Petzold CJ, Lee TS. Metabolic engineering of Escherichia coli for limonene and perillyl alcohol production. Metab Eng. 2013;19:33-41.

55. Cao X, LV Y-B, Chen J, Imanaka T, Wei L-J, Hua Q. Metabolic engineering of oleaginous yeast Yarrowia lipolytica for limonene overproduction. Biotechnol Biofuels. 2016;9(1):214

56. Carter OA, Peters RJ, Croteau R. Monoterpene biosynthesis pathway construction in Escherichia coli. Phytochemistry. 2003;64(2):425-33.

57. Du FL, Yu HL, Xu JH, Li CX. Enhanced limonene production by optimizing the expression of limonene biosynthesis and MEP pathway genes in $E$. coli. Bioresour Bioprocess. 2014;1 (1):10.

58. Duetz WA, Bouwmeester $H$, Beilen JB, Witholt B. Biotransformation of limonene by bacteria, fungi, yeasts, and plants. Appl Microbiol Biotechnol. 2003;61(4):269-77.

59. Liao JC, Mi L, Pontrelli S, Luo S. Fuelling the future: microbial engineering for the production of sustainable biofuels. Nat Rev Microbiol. 2016;14(5):288-304.

60. Jongedijk E, Cankar K, Ranzijn J, van der Krol S, Bouwmeester H, Beekwilder $\mathrm{J}$. Capturing of the monoterpene olefin limonene produced in Saccharomyces cerevisiae. Yeast. 2015;32(1):159-71.

61. Willrodt C, David C, Cornelissen S, Bühler B, Julsing MK, Schmid A. Engineering the productivity of recombinant Escherichia coli for limonene formation from glycerol in minimal media. Biotechnol J. 2014;9(8):1000-12.

62. Behrendorff JBYH, Vickers CE, Chrysanthopoulos P, Nielsen LK. 2,2-Diphenyl-1-picrylhydrazyl as a screening tool for recombinant monoterpene biosynthesis. Microb Cell Fact. 2013:12(1):76.

63. Ignea C, Pontini M, Maffei ME, Makris AM, Kampranis SC. Engineering monoterpene production in yeast using a synthetic dominant negative geranyl diphosphate synthase. ACS Synth Biol. 2014;3(5):298-306.
64. Kiyota H, Okuda Y, Ito M, Hirai MY, Ikeuchi M. Engineering of cyanobacteria for the photosynthetic production of limonene from $\mathrm{CO}_{2}$.J Biotechnol. 2014:185:1-7.

65. Vararu F, Moreno-Garcia J, Moreno J, Niculaua M, Nechita B, Zamfir C, Colibaba C, Dumitru G-D, Cotea W. Minor volatile compounds profiles of 'aligoté' wines fermented with different yeast strains. Not Sci Biol. 2015;7(71):123-8

66. Humbird D, Davis R, Tao L, Kinchin C, Hsu D, Aden A, Schoen P, Lukas J, Olthof B, Worley M, Sexton D, Dudgeon D. Process design and economics for biochemical conversion of lignocellulosic biomass to ethanol: diluteacid pretreatment and enzymatic hydrolysis of corn stover. CO: Golden; 2011.

67. Norman AG, Stotzky G. Microbial Respiration. Methods Soil Anal. 1965;9:1550-72.

68. Bailey J, Ollis D. Biochemical engineering fundamentals. New York: Chemical Engineering Education; 1976.

69. Intelligen, "SuperPro Designer". 2013.

70. Perry RH, Green DW, Maloney JO. Perry's chemical engineers' handbook. New York: Mc Graw-Hills; 1997.

71. Wu W, Yenkie K, Maravelias CT. A superstructure-based framework for bio-separation network synthesis. Comput Chem Eng. 2017;96:1-17.

72. Yenkie KM, Wu WZ, Clark RL, Pfleger BF, Root TW, Maravelias CT. A roadmap for the synthesis of separation networks for the recovery of biobased chemicals: matching biological and process feasibility. Biotechnol Adv. 2016;34(8):1362-83.

73. Harrison RG, Todd P, Rudge SR, Petrides DP. Bioseparations science and engineering, vol. 2. Oxford: Oxford University Press; 2003.

74. Huang HJ, Ramaswamy S, Tschirner UW, Ramarao BV. A review of separation technologies in current and future biorefineries. Sep Purif Technol. 2008;62(1):1-21.

75. Lightfoot EN, Moscariello JS. Bioseparations. Biotechnol Bioeng. 2004;87(3):259-73.

76. Yenkie KM, Wu W, Maravelias CT. Synthesis and analysis of separation networks for the recovery of intracellular chemicals generated from microbial-based conversions. Biotechnol Biofuels. 2017:10(1):119.

77. Wu W, Yenkie K, Maravelias C. Synthesis and analysis of separation processes for extracellular chemicals generated from microbial conversions. Biotechnol Biofuels. 2018. (submitted).

78. Shao P, Ma H, Qiu Q, Jing W. Physical stability of R-(+)-limonene emulsions stabilized by Ulva fasciata algae polysaccharide. Int J Biol Macromol. 2016;92:926-34.

79. Brandt K, Schembecker G. Production rate-dependent key performance indicators for a systematic design of biochemical downstream processes. Chem Eng Technol. 2016;39(2):354-64.

80. Davies FK, Work VH, Beliaev AS, Posewitz MC. Engineering limonene and bisabolene production in wild type and a glycogen-deficient mutant of Synechococcus sp. PCC 7002. Front Bioeng Biotechnol. 2014;2:1-11.

81. Dunlop MJ, Dossani ZY, Szmidt HL, Chu HC, Lee TS, Keasling JD, Hadi MZ, Mukhopadhyay A. Engineering microbial biofuel tolerance and export using efflux pumps. Mol Syst Biol. 2011;7:487.

Ready to submit your research? Choose BMC and benefit from:

- fast, convenient online submission

- thorough peer review by experienced researchers in your field

- rapid publication on acceptance

- support for research data, including large and complex data types

- gold Open Access which fosters wider collaboration and increased citations

- maximum visibility for your research: over 100M website views per year

At BMC, research is always in progress.

Learn more biomedcentral.com/submissions 